\title{
Lowe's syndrome: identification of carriers by lens examination
}

\author{
R. J. M. GARDNER* and NICHOLAS BROWN \\ From the MRC Clinical Genetics Unit, Institute of Child Health, London, and the Institute of Ophthalmology, London
}

\begin{abstract}
Summary. Lens examinations were performed on 7 obligate and 7 possible carriers of the X-linked gene for Lowe's syndrome, and on 117 controls. By quantitatively grading punctate cortical opacities, it was possible to discriminate between the obligate carriers and the controls with a fair degree of confidence. In the age group most important for genetic counselling, that of child bearing, the data are too limited for the derivation of precise estimates, but may, nevertheless, be useful. More such data are needed.
\end{abstract}

There have been conflicting views upon the value of a lens examination in determining whether or not a woman is a carrier of the X-linked gene for Lowe's syndrome (Holmes et al, 1969). Punctate opacities are often seen in obligate and possible heterozygotes, but are also frequent in the general population. We here describe how a quantitative assessment of punctate cortical opacities may be useful as a discriminant.

\section{Subjects for study}

Patients with Lowe's syndrome were found with the help of Professor C. E. Dent of University College Hospital, London; Mr B. Jay of Moorfields Eye Hospital, London; Dr R. Lax of the KennedyGalton Centre, Radlett; Dr J. Spears in general practice in Coventry; and from the records of the Hospital for Sick Children, London, and of the MRC Clinical Genetics Unit. Nine families were thus discovered. Apart from the case of one adopted boy and of one girl with a Lowe's syndrome phenotype, it was possible to get in touch with all the families, and to arrange for at least the mother to have an eye examination. Abbreviated pedigrees of these 7 families are depicted in Fig. 1. Brief clinical histories of the affected children follow.

\section{Family C}

The index case, J.C., was born on 27 July 1961.

Received 26 September 1975.

* Present address: The Hospital for Sick Children, Toronto, Canada.
He weighed $3.4 \mathrm{~kg}$ at birth, but gained slowly thereafter, and by 10 weeks his weight was below the third centile. At 5 months, bilateral cataracts were discovered. On examination at 6 months he showed signs of mental and motor retardation and had the typical bulging forehead and sunken eyes of Lowe's syndrome. Muscle tone was reduced. $X$-ray examination of ribs and wrists revealed osteoporosis and changes associated with rickets. There was an acidosis (serum bicarbonate 31.3 vol. \%; equivalent to $14.0 \mathrm{mmol} / \mathrm{l}$ ). A urinary chromatogram showed an excess of several amino acids, notably glutamine, taurine, and glycine, and an intense spot migrating as ornithine. He was never able to pull himself up or sit unsupported, and never learnt to feed himself. He died on 23 January 1964 of an acute upper respiratory tract infection.

His mother's brother, R.W. (I :2), seems likely to have had the same condition. He had bilateral congenital cataracts, and was weak and limp. $\mathrm{He}$ was never able to sit up by himself. He is reputed to have had 'exactly the same appearance' as J.C. He died aged $2 \frac{1}{2}$ years during a cataract operation.

\section{Family $\mathbf{H}$}

The index case, R.H., was born on 23 September 1949. He has been the subject of a case report by Dent and Smellie (1961) and by Greaves (1963). He has since died aged 19. His younger brother, similarly affected, died aged 10 . His sister has had two sons, the younger of whom (I.M.R., born 25 January 1974) has Lowe's syndrome. 

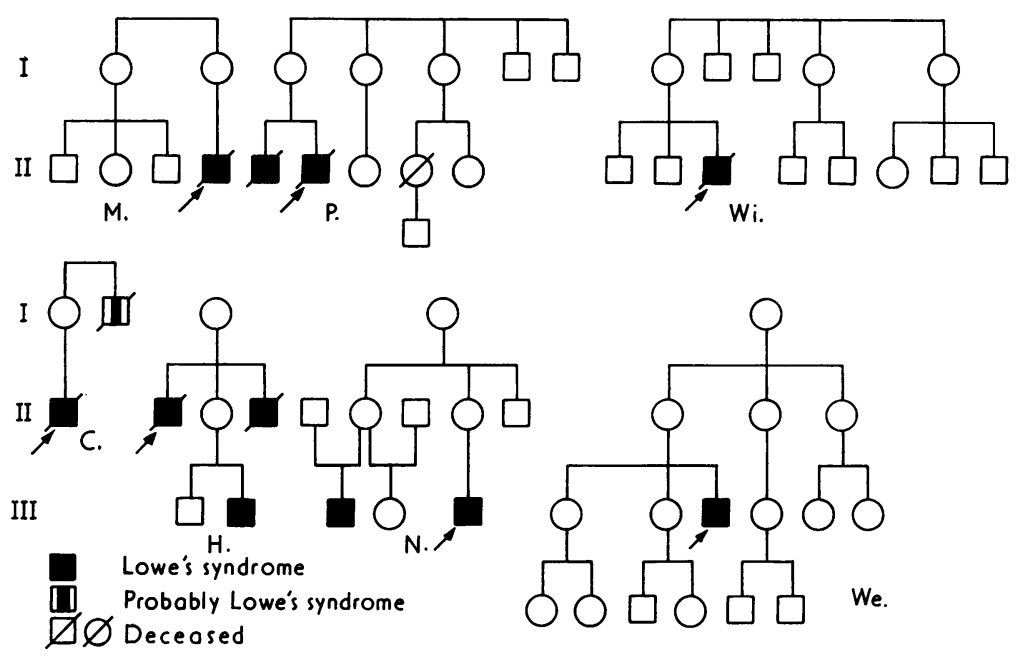

FIG. 1. The families.

\section{Family $M$}

The index case, D.K.M., was born at term on 12 February 1963, weighing $2.8 \mathrm{~kg}$. He was noted to be persistently hypotonic, and was difficult to feed. His condition was fully investigated at 3 months, when bilateral cataract, pinpoint pupils, generalized aminoaciduria, glycosuria and proteinuria, a raised blood urea $(7.8 \mathrm{mmol} / \mathrm{l})$, and a persistently low bicarbonate $(10-17 \mathrm{mmol} / \mathrm{l})$ were found. At $4 \frac{1}{2}$ months his height and weight were at the third centile, and he remained hypotonic, unable to sit or support his head. Urine chromatography showed a particular excess of small molecular weight amino acids. On $x$-ray examination there was early rickets at the distal epiphyses of the tibia and fibula. Goniotomy for bilateral glaucoma was done at $5 \frac{1}{2}$ months. He is now (1974), at 11, virtually totally blind, and severely mentally retarded. $\mathrm{He}$ is $114 \mathrm{~cm}$ tall and weighs $26.2 \mathrm{~kg}$. He does not obey simple commands, and 'speech' consists of grunting. He is doubly incontinent, and has to be fed. Though he walked at 6 years, he is now nearly confined to a wheelchair. The parents are not related, and there is no family history of similarly affected children.

\section{Family $\mathbf{N}$}

The index case, C.M.N., was born on 17 January 1965. He weighed $4.1 \mathrm{~kg}$. Bilateral cataracts were seen at 4 months; the pupils were miotic. Motor and mental development have been very retarded. By $3 \frac{1}{2}$ years he was pulling himself up to a standing position, and he only began to walk, unsteadily, at 6 years. He started talking in monosyllables at $2 \frac{1}{2}$ years, and by 3 could converse with his mother in short but relevant sentences. His developmental quotient at 3.2 years was 39 , and at 4.4 years, 32 . His weight has been around the 50th centile up to 6 years, and below it thereafter; his height has been at the tenth centile. Wrist $x$-ray examination at 10 months showed active rickets; this has responded too treatment with vitamin $D$. Urine chromatography at 10 months showed a generalized nonspecific in crease in amino acid excretion.

His mother's sister's son, F. de S., was born one month prematurely on 12 May 1956, weighing $2.1 \mathrm{~kg}$. His early development was retarded. At 6 months his weight was well below the third centile, and he was described as a flabby atonic baby, taking little notice of anything around him, and making no attempt to hold his head up. The diagnosis of bilateral cataract was made at this time; the examination was difficult because of miosis. At 9 years his mental age was estimated to be 3 . Urine examination at this time showed proteinuria of $0.6 \mathrm{~g} / \mathrm{l}$. His condition has been gradually deteriorating, and he is now (1974) wasted, lethargic, and unresponsive. $\mathrm{He}$ has had major fits over recent years. $X$-ray examinations have shown abnormalities of bone structure and poor mineralization, but no rickets. On urine chromatography in 1974 there was a generalized non-specific aminoaciduria typical of Lowe's syndrome.

\section{Family $\mathbf{P}$}

The index case, B.P., born on 22 February 1941, was the subject of a case report by Dent and Smellie 
in 1961, and by Greaves in 1963. He has since died at the age of 33 . His elder brother, similarly affected, died in 1948 aged $9 . \quad$ A third pregnancy was terminated at 3 months' gestation because of a presumed high genetic risk. The parents were not related, and there is no family history of similar defects.

\section{Family We}

The index case, P.R.W., was born on 13 October 1958. Bilateral cataracts were seen at birth, and he had several eye operations up to 3 years. Mental and motor development have been retarded. $\mathrm{He}$ was psychometrically assessed at 7 years, and considered to be functioning at a 1 to $1 \frac{1}{2}$ year level. $\mathrm{He}$ had congenital dislocation of the hip; it was during an episode of dehydration after a hip operation in 1963 that the diagnosis of Lowe's syndrome was first suspected, on the basis of a typical facial appearance. Hypotonia was noted at the time. Three urinary chromatograms were normal, but one showed 'a mild degree of aminoaciduria'. He did not have rickets. Slight acidosis was seen in 1964, when his alkali reserve was $14.1 \mathrm{mEq} / 1$ (equivalent to 14.1 $\mathrm{mmol} / \mathrm{l}$ serum bicarbonate). A urine specimen examined in 1974 had a moderate non-specific aminoaciduria, with a 'central cluster' pattern. His present (1974) height, at the age of 15 , is $124 \mathrm{~cm}$, and his appearance is that of a wizened 8-year-old. There is no family history of similarly affected children, and the parents are unrelated.

\section{Family Wi}

The index case, L.W., was born on 22 August 1956, the third son of unrelated parents. He was the subject of a report by Dundas (1964). He has since died aged 9. A cousin, his mother's sister's son (II.8), at present aged 2 , is said to have eye trouble; we were unable to trace this boy. There is no other family history of note.

The control subjects were 117 patients aged from 5 to 78 attending Moorfields Eye Hospital for reasons of referral other than cataract, and in whom mydriasis was necessary.

\section{Method}

Mydriasis was obtained with cyclopentolate $1 \%$ and phenylephrine $10 \%$ eyedrops, two applications of each over the course of 20 minutes. The subjects were then examined at the slit-lamp microscope, and their lenses photographed by the techniques of slit-image photography (Brown, 1972a, b) and of macrophotography (Brown, 1970). The distribution and quantity of the opacities on frontal and sagittal view were recorded on a sketch. Lenses were scored on a $\mathrm{O}$ to ++++ grading according to the numbers of punctate cortical opacities per quadrant, as shown in Fig. 2.

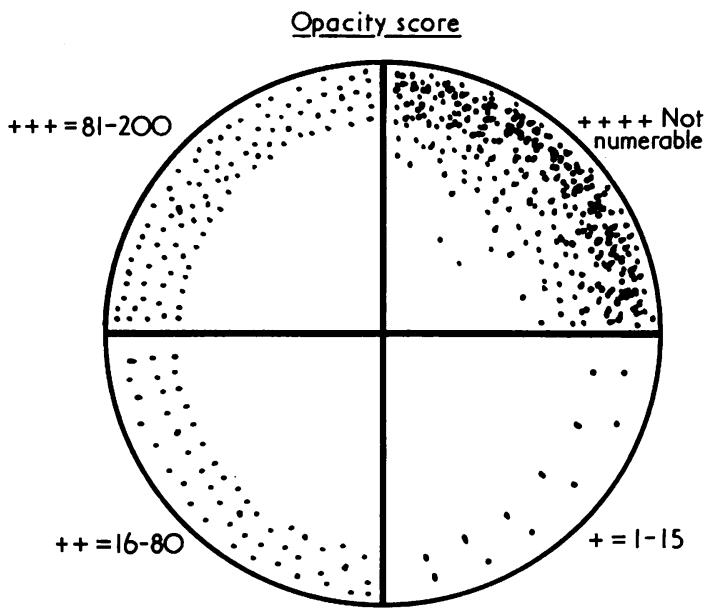

FIg. 2. Criteria for scoring punctate cortical opacities (number of opacities per quadrant of lens).

\section{Results}

Seven obligate and seven possible carriers were examined. The scoring of opacities is set out in Table I. Examples of the appearance of a,+++ ,

TABLE I

LENS FINDINGS IN OBLIGATE AND POSSIBLE LOWE HETEROZYGOTES

\begin{tabular}{|c|c|c|c|c|c|}
\hline $\begin{array}{c}\text { Individual } \\
\text { (see Fig. 1) }\end{array}$ & $\begin{array}{c}\text { Age } \\
(y)\end{array}$ & pC & $\begin{array}{l}\text { Punctate Cortical } \\
\text { Opacity Score }\end{array}$ & $\mathrm{pN}$ & AS \\
\hline $\begin{array}{lr}\text { C. } & \text { I.1 } \\
\text { H. } & \text { I.1 } \\
\text { H. } & \text { II.2 } \\
\text { N. } & \text { I.1 } \\
\text { N. } & \text { II.2 } \\
\text { N. } & \text { II.4 } \\
\text { P. } & \text { I.1 } \\
\text { M. } & \text { I.2 } \\
\text { N. } & \text { III.2 } \\
\text { We. } & \text { I.1 } \\
\text { We. } & \text { II.1 } \\
\text { We. } & \text { II.2 } \\
\text { We. } & \text { III.2 } \\
\text { Wi. } & \text { I.1 }\end{array}$ & $\begin{array}{r}42 \\
54 \\
22 \\
71 \\
41 \\
39 \\
61 \\
42 \\
9 \\
70 \\
46 \\
47 \\
22 \\
47\end{array}$ & $\begin{array}{l}1 \\
1 \\
1 \\
1 \\
1 \\
1 \\
1 \\
0.67 \\
0.50 \\
0.30 \\
0.60 \\
0.10 \\
0.20 \\
0.33\end{array}$ & $\begin{array}{c}+++ \\
+++ \\
+++ \\
+++ \\
+++ \\
++ \\
+++ \\
+ \\
+ \\
+++ \\
+++ \\
++ \\
++ \\
+++\end{array}$ & $\begin{array}{l}0.12 \\
0.12 \\
0 \\
0 \\
0.12 \\
0.10 \\
0 \\
0.95 \\
0.38 \\
0 \\
0.12 \\
0.23 \\
0.10 \\
0.12\end{array}$ & $\begin{array}{l}+ \\
+ \\
\mathbf{O} \\
+ \\
\mathbf{0} \\
+ \\
+ \\
+ \\
+ \\
+ \\
+ \\
+ \\
+ \\
+\end{array}$ \\
\hline
\end{tabular}

pC $=$ pre-examination probability of being a carrier (see text); $\mathrm{pN}=$ probability of a control of the same age group having an opacity score as great or greater than this (from Table II); AS = apical sparing of opacities.

+++ , and ++++ lens segment on macrophotography are illustrated in Fig. 3. A retroilluminated +++ whole lens is illustrated in Fig. 4. No carrier, obligate or possible, had a completely clear lens, though in several the opacities were con- 


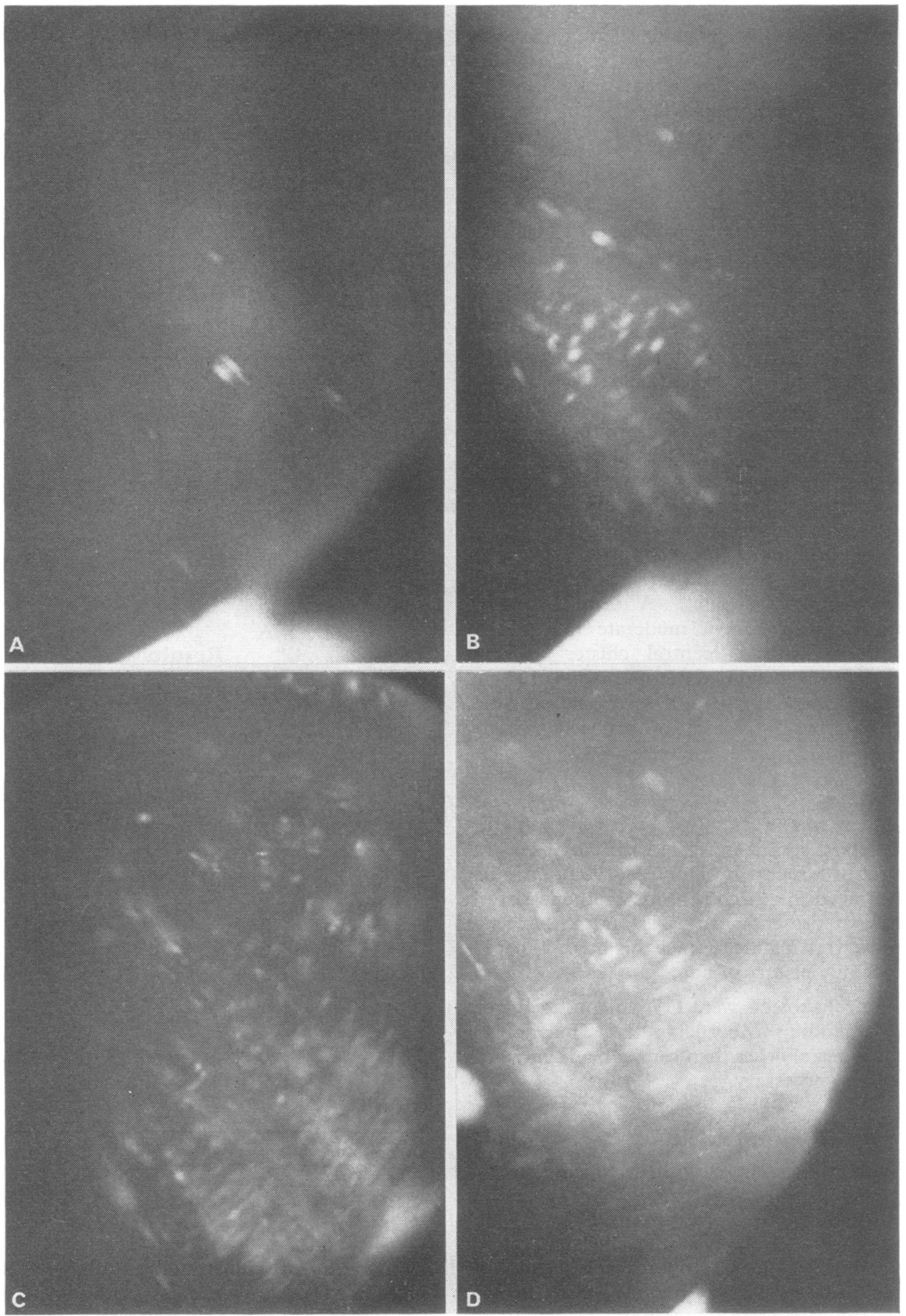

$\vec{\circ}$

$\ddot{\vec{H}}$

$\vec{\omega}$

今.

$+\vec{t}$

FIG. 3. (A) The appearance of a + affected lens on macrophotography; (B) ++ ; (C) +++ ; (D) ++++ 


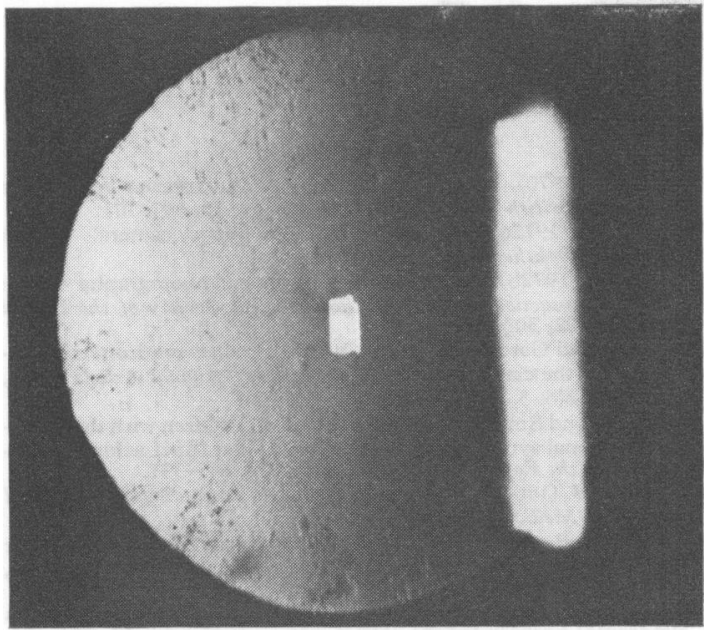

FIG. 4. Appearance of a $t+t$ whole lens upon retroillumination.

fined to the periphery. The pre-examination probability that each subject is a carrier (pC) is noted in Table I; this is derived from the pedigree, calculated, where appropriate, by the method described by Murphy and Mutalik (1969). We have given for each subject the probability of a control of the same age group having an opacity score as great or greater than the subject $(\mathrm{pN})$; this is taken from Table II.

TABLE II

INCIDENCE OF PUNCTATE CORTICAL OPACITIES BY AGE IN CONTROLS

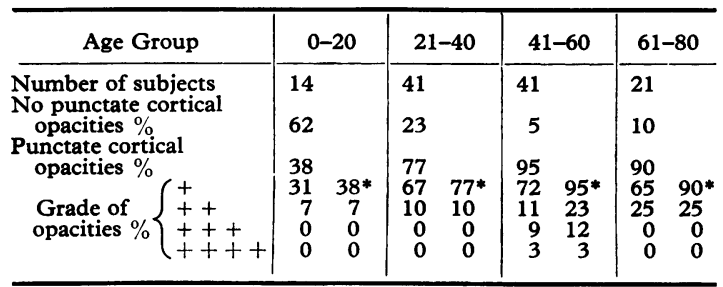

* Cumulative percentages of those with an opacity score as great or greater than the given score.

The findings in the controls' eyes, according to age, are set out in Table II. In both the carriers and the controls there was virtually complete correlation of opacity scores between eyes in individuals; the sole exception was one control ++ in one eye and +++ in the other (entered as half a person in the ++ and +++ rows in Table II).

\section{Discussion}

It became clear to us, from reading the published reports and as our own study proceeded, that the mere presence or absence of lenticular opacities was of little use in helping in the identification of Lowe heterozygotes. Further, the appearance of the opacities in our obligate carriers was no different from those controls who had as many opacities. These aspects of our work are dealt with in a companion publication (Brown and Gardner, 1976).

The number of punctate cortical opacities is another matter. Most of the obligate carriers had many, with a score of +++ , and most of the controls had few, scoring ++ or less. With either the ++ or +++ level as the cut-off, there is a clear separation between the two groups, when the $95 \%$ confidence limits of the proportions are considered (Table III). Presumably, this phenotypic hetero-

TABLE III

SEPARATION OF OBLIGATE CARRIERS AND CONTROLS ON OPACITY SCORE

\begin{tabular}{c|c|c}
\hline Opacity Score & $\geqslant+++$ & $\geqslant++$ \\
\hline $\begin{array}{c}\text { Proportion of obligate } \\
\text { carriers in this class } \\
(\mathrm{N}=7)\end{array}$ & $86 \%(42-100 \%)$ & $100 \%(59-100 \%)$ \\
$\begin{array}{c}\text { Proportion of controls } \\
\text { in this class }(\mathrm{N}=117)\end{array}$ & $3 \%(1-8 \%)$ & $18 \%(12-26 \%)$ \\
\hline
\end{tabular}

The $95 \%$ confidence limits of the distribution of the probability are given in brackets (taken from Documenta Geigy, 7 th ed., 1970, pp. 85 and 99).

geneity is a true reflection of the genetic heterogeneity of the two populations.

The increasing incidence of cortical opacities with age, certainly in normals, and very likely in Lowe heterozygotes, hampers the calculation of figures of use to the genetic counsellor. Clearly, each age group must be considered on its own. Only 41 (one-third) of our controls were in the important 21 to 40 age group, and 2 of the obligate carriers. Four of these 41 controls scored ++ : the remainder were + or had no punctate cortical opacities. One 22-year-old obligate carrier scored +++ , and one 39-year-old scored ++ . The impression from published material is that most but not all obligate carriers, who are stated to be or who are likely to be in their 20's and 30's, have punctate cortical opacities (Table $\mathrm{V}$ in Brown and Gardner). Where the description of the eye findings is detailed, many of these seem likely to have had a ++ or higher score. We are reluctant to glean extra information from possible carriers.

Our numbers are, we conclude, too small for us to derive accurate estimates of the incidences of cortical opacities in at least the Lowe heterozygotes of the 21 to 40 age group. For the present, we would hazard the opinion that young women carrying the 'Lowe gene' are likely to have an opacity 
score of at least ++ , while normal homozygotes are unlikely to score above + . We should emphasize that the eye must be examined with the pupil fully dilated; in 5 out of our 7 obligate carriers the opacities were to be seen only in the periphery of the lens. We hope that in future those who examine Lowe heterozygotes will describe their patients in such detail as we have, against the day when a specific biochemical test shall have rendered this approach outmoded.

We thank the many doctors who have provided us with information on the patients with Lowe's syndrome whose families we have studied, and who have otherwise assisted us: those we have mentioned in the text, Dr S. K. Dutta, Dr M. Friedman, Dr M. C. Handscombe, Dr B. Stone, Dr E. G. Taylor, Dr P. G. Wallis, Dr H. Parry Williams, and those whose observations made some years ago have been gleaned from hospital records. We are grateful to Professor C. O. Carter for helpful criticisms and suggestions. We thank the relatives, without whose co-operation this study would not have been possible. R.J.M.G. has had the support of a New Zealand MRC Training Fellowship.

REFRRENCES

Brown, N. (1970). Macrophotography of the anterior segment of the eye. British fournal of Ophthalmology, 54, 697-701.

Brown, N. (1972a). An advanced slit image camera. British fournal of Ophthalmology, 56, 624-631.

Brown, N. (1972b). Quantitative slit image photography of the lens. Transactions of the Ophthalmological Society of the United Kingdom, 92, 303-317.

Brown, N. and Gardner, R. J. M. (1976). Lowe's syndrome: identification of the carrier state. Birth Defects: Original Article Series, Vol. XII, No. 3, pp. 579-591.

Dent, C. E. and Smellie, J. M. (1961). Two children with the oculocerebro-renal syndrome of Lowe, Terrey and MacLachlan. Proceedings of the Royal Society of Medicine, 54, 335-337.

Dundas, J. B. (1964). Lowe's syndrome. Proceedings of the Royal Society of Medicine, 57, 837.

Greaves, D. P. (1963). Symposium on metabolic diseases of the eye, cystinosis. Proceedings of the Royal Society of Medicine, 56, 25-26.

Holmes, L. B., McGowan, B. L., and Efron, M. L. (1969). Lowe's syndrome: a search for the carrier state. Pediatrics, 44, 358-364.

Murphy, E. A. and Mutalik, G. S. (1969). The application of Bayesian methods in genetic counselling. Human Heredity, 19, 126-151. 